\title{
Letters
}

Website: bmj.com

\section{Copying letters to patients}

\section{Concerns of clinicians and patients need} to be addressed first

EDITOR-Chantler and Johnson suggested that patients should receive copies of letters and summaries. ${ }^{1}$ We have researched this subject in our practice since 1998. ${ }^{2}$ Our experience of copying referral letters received such a positive response from patients that we have been doing this routinely for the past year and a half.

In a recent postal survey of 300 patients who had received copies of letters, 229 replied (response rate $76 \%$ ), $220(97 \%)$ of them saying that they would like to receive copies in future. Most of the respondents $(184,80 \%)$ believed that this should become routine NHS policy and should receive priority funding. Few concerns were raised about understanding the letters, and patients did not report increased anxiety; rather, they were reassured that their problem was being dealt with and they could understand why they were being referred.

Copying letters has not notably increased workload for doctors in our practice in terms of extra consulting time with patients, but financial costs are incurred in additional administrative time, stationery, and postage. We therefore broadly agree with Chantler and Johnson's argument that this is a policy that, if adequately funded, should be implemented forthwith.

We have, however, also just completed a series of interviews with a random sample of local general practitioners, all of whom raised some important concerns. They worry about how to write letters that are both comprehensible for patients and informative for professional colleagues, and how to avoid anxiety in patients when writing about tentative but potentially serious differential diagnoses. Issues about

\section{Advice to authors}

We would like to receive all responses electronically at our website. Please send your letter directly to bmj.com as a rapid response to a published article.

All rapid responses will be considered for publication in the paper journal; authors will be notified by email if their rapid response has been accepted, but not otherwise.

For more detailed advice please see bmj.com/advice/sections.shtm\#letters

bmj.com administrative resources also arise, and the question of maintaining the confidentiality of letters, especially for people who change addresses often. Particular patient groups who may have particular difficulties in accessing and understanding written correspondence include those with educational or visual disabilities, those with mental health problems, and those who do not have adequate reading skills in English.

Despite our wish to see this policy implemented nationally as soon as possible, we believe that it would be counterproductive to do this without first addressing the considerable concerns of both clinicians and certain patient groups. We hope that the pilot studies being funded by the Department of Health will identify the means of addressing these key issues and thus enable the successful implementation of this key initiative.

Diana Jelley general practitioner

Tim van Zwanenberg general practitioner Caron Walker research and development facilitator,

North Tyneside Research Primary Care Trust

Collingwood Surgery, Hawkeys Lane, North

Shields NE29 0S

1 Chantler C, Johnson J. Patients should receive copies of letters and summaries. BMJ 2002;325:388-9. (17 August.) 2 Jelley D, van Zwanenberg T. Copying GP referral letters to patients-study of patients views. Br J Gen Pract 2000;50

\section{Policy should be implemented as soon as} possible

EDITOR-A year ago I chaired a multidisciplinary working group to advise officials at the Department of Health on implementing the policy in the NHS Plan that patients should receive copies of clinicians' letters about them. The group included clinicians, patients, administrators, researchers, and others. Its report was published on the Department of Health's website in March 2002 (www.doh.gov.uk/patientletters/ issues.htm). Many organisations and individuals in the NHS are either already copying letters to patients, or keen to do so. Many have found the working group's report helpful in moving forward while more detailed guidelines are awaited from the department.

Chantler and Johnson's letter gives welcome recognition to the importance of this initiative. ${ }^{1}$ They refer with concern to a recommendation by the working group for further research. I would like to reassure them that the short term pilot projects now under way are intended as action research to help roll out the policy and inform particular aspects of the guidelines that need closer attention. They include issues around people who lack the mental capacity to give consent and people with different kinds of communication difficulties, among others

I share their concern that this policy be rolled out as quickly as possible. I am committed to its importance as one means of improved communications with patients, enhancing their ability to share in the decision making process about their care and treatment and to make informed choices. But it is clear from the working group's debates that the many disparate organisations and institutions of the NHS are at very different starting points for implementation. It is encouraging that so many are anxious to continue or begin their efforts in this field, and that guidelines will be issued in the new year to bring others on board. I hope all those interested will read the working group's report

Barbara L Meredith policy and communications manager

Age Concern London, London SE5 9QY

bmeredith@aclondon.org.uk

1 Chantler C, Johnson J. Patients should receive copies of letters and summaries. BMJ 2002;325:388-9. (17 August.)

\section{No one really cares}

EDitor-Chantler and Johnson urge that patients should receive copies of letters and summaries. ${ }^{1}$ For the past six years our eye department has been providing patients with a copy of their computer generated surgical discharge summary at the time of ward discharge. This is helpful when the case notes are missing at their follow up visit, ensures that postoperative treatment is prescribed legibly and in plain English, and includes OPCS4 (Office of Population Censuses and Surveys, fourth version) and ICD-10 (international classification of diseases, 10th revision) codes with 100\% accuracy, according to a recent audit. Surgical complications and additional surgical procedures are also clearly stated, which ensures that these problems can be openly discussed with patients and their relatives.

We have generated more than 7000 such summaries and have received one letter of support from a local general practitioner congratulating us on the format of the summary. Most patients who have experienced complicated surgery ask for further information, and most are satisfied with the explanation provided. We have not yet been asked for a discharge summary in another language, which would probably 
exceed the capabilities of our $25 \mathrm{MHz}$ 486SX personal computer.

When I was a house officer at Aberdeen Royal Infirmary in 1979, working for the late Professor Jim Petrie, discharge summaries were computer generated, although patients were not given a copy. We do not seem to have made a great deal of progress, and I share Chantler and Johnson's scepticism that further research is necessary before recommending the practice nationally. Unfortunately our experience shows that even when legible, accurate, and timely summaries are provided, no one really cares.

Hamish M A Towler consultant ophthalmologist Whipps Cross University Hospital, London E11 1NR

hmat@hmatowler.co.uk

1 Chantler C, Johnson J. Patients should receive copies of letters and summaries. BMJ 2002;325:388-9. (17 August.)

\section{Comparison of different measures of blood pressure}

\section{Use sphygmomanometers more, not less}

EDITOR-Little et al in their study have shown that doctors' measurements of blood pressure are much higher than those taken by nurses, by the patient at home, or by ambulatory monitoring. ${ }^{1}$ From this they conclude that conventional measurements by general practitioners may be misleading in guiding treatment decisions. We believe, however, that this conclusion runs ahead of the evidence.

The chain of research evidence that is required to make this conclusion has three links. The first link is finding a reliable method of measuring blood pressure; the second link is showing that raised blood pressure diagnosed by the chosen method increases the patient's risk of a cardiovascular event; the last link is showing that treatment reduces the risk. Knowing the absolute benefits of treatment and what target blood pressure to aim for are valuable parts of the last link.

Our concern is that the research evidence for treatment decisions based on newer methods is not available for the last link. We know from well conducted trials that treatment based on clinic readings reduces risk. ${ }^{23}$ Additionally, these trials have given us evidence to support a target for treatment. This evidence is much weaker for newer methods of diagnosing and monitoring hypertension. In essence we have two different diagnoses: hypertension diagnosed conventionally and hypertension diagnosed otherwise. The epidemiology of hypertension diagnosed otherwise is currently much less understood.

Why are doctors' measurements higher than the other methods? The study did not address this but it is also important in extrapolating from the results of Little et al. One possibility is that the stakes are higher for the patient in a consultation with a doctor. This is presumably because the doctor has the power to label the patient with a diagnosis and to suggest and prescribe treatment. If we assume that this psychological stress underlies the raised measurements, ${ }^{4}$ then transferring the responsibility for measurement (and by inference diagnosis) to practice nurses may be self defeating as the concern may be transferred too. Doctors should not discard their sphygmomanometers-or give them to their nurses-rather, they should use them more so that clinical decisions are based on multiple readings. In this aspect we are wholly in agreement with the authors.

William T Hamilton research fellow

w.t.hamilton@btopenworld.com

Deborah Sharp professor

Division of Primary Care, University of Bristol, Bristol BS6 6JL

1 Little P, Barnett J, Barnsley L, Marjoram J FitzgeraldBarron A, Mant D. Comparison of agreement between difA ferent measures of blood pressure in prinary care and daytime a (3 August)

2 Hansson I Zanchetti A Carruthers SG, Dahlof B, Elmfeldt D, Julius S, et al. Effects of intensive bloodpressure lowering and low-dose aspirin in patients wit hypertension: principal results of the Hypertension Optimal Treatment (HOT) randomised trial. Lance 1998;351:1755-62.

3 UK Prospective Diabetes Study Group. Tight blood pressure control and risk of macrovascular and microvascular complications in type 2 diabetes: UKPDS $38 . B M$ 1998;317:703-13.

4 Carroll D, Davey Smith G, Sheffield D, Shipley MJ, Marmo MG. Pressor reactions to psychological stress an presiction of future blood pressure: data from the Whitehall II study. BMJ 1995;310:771-5.

\section{Blood pressure measurement causes problems in clinical practice}

EDITOR-After a lifetime of clinical blood pressure measurement and making decisions based on such measurements Little et al's article is likely to be greeted with incredulity. ${ }^{1}$ But they have clearly shown important problems with blood pressure measurement.

Blood pressure measurement is subject to systematic and random error. Research evidence on the relation between blood pressure and risk of coronary heart disease is based on clinic measurements taken after 5 minutes' rest seated and using calibrated equipment. $^{2}$

In clinical practice blood pressure may be measured opportunistically (when pain, anxiety, or malaise affect blood pressure), in a hurry (with inadequate rest periods), or in expectation of a blood test, which increases blood pressure, ${ }^{3}$ and usually with uncalibrated equipment. ${ }^{4}$ Overestimation is likely under these conditions. Little et al have empirically confirmed this systematic error.

Blood pressure also shows biological variation within individuals. A single measurement of blood pressure should more correctly be quoted with a $95 \%$ confidence interval equivalent to $18 \%$ of its value (J M Wright and VJ Musini, eighth international Cochrane colloquium, Cape Town, October 2000). In epidemiological studies the effects of random error (regression dilution bias due to variability of blood pressure in each person) are corrected for during analysis; in clinical trials the effects of random error are eliminated by comparing blood pressures with a control group. In clinical practice, however, changes in blood pressure from treatment are assessed on the basis of a few measurements. In practice this means that deciding whether a patient has achieved a target systolic blood pressure of (for example) $140 \mathrm{~mm} \mathrm{Hg}$ is subject to a great deal of error. A patient whose true mean systolic blood pressure is $130 \mathrm{~mm} \mathrm{Hg}$ will on one in six occasions give a reading of over $140 \mathrm{~mm} \mathrm{Hg}$. With regular follow up, it is only a matter of time before a second treatment is added or the dose increased.

Perhaps it is time to rethink the concept of target blood pressures in the light of an understanding of biological variation. Perhaps it is also time to rethink the follow up of treated patients. We know that antihypertensive drugs work from the experience of many clinical trials in which thousands of patients had repeated blood pressure measurements. A few measurements taken from one person are more likely to be misleading than informative. If we really need to know the effect of treatment in an individual patient we need more than 10 measurements before and after treatment.

Tom Marshall lecturer in public health medicine Birmingham University, Birmingham B15 2TT T.P.Marshall@bham.ac.uk Barron A, Mant D. Comparison of agreement between different measures of blood pressure in primary care and daytime ambulatory blood pressure. BMJ 2002;325:254-9. (3 August.)

2 Bakx JC, Netea RT, van den Hoogen HJM, Oerlemans G, van Dijk R, van den Bosch WJHM, et al. De invloed van een rustperiode op de bloeddruk. [The influence of a rest period on blood pressure measurement.] Huisarts en Wetenschap 1999;42:53-6.

3 Marshall T, Anantharachagan A, Choudhary K, Chue C, Kaur I. A randomised controlled trial of the effect of anticipation of a blood test on blood pressure. J Hum Hypertens 2002 (in press).

4 Rouse A, Marshall T. The extent and implications of sphygmomanometer calibration error in primary care. JHum Hypertens 2001;15:587-92.

\section{Ambulatory blood pressure may not be gold standard}

EDitor-Although Little et al's study comparing so many measures of blood pressure was interesting, they should have limited their inferences and comments to the comparison between values. ${ }^{1}$

The interpretation of their results is based on the assumption that ambulatory blood pressure is the gold standard in assessing a subject's blood pressure. To support this statement Little et al quote several papers that claimed that ambulatory blood pressure is superior to clinic blood pressure in predicting outcome. In fact the studies showed that ambulatory blood pressure has a greater predictive value than a few clinic readings taken at one or two visits.

But if clinic blood pressure is measured several times over an adequate period of observation, as suggested by current guidelines of scientific societies for patients with newly diagnosed mild hypertension, its predictive power may be superior to that of ambulatory measurement. ${ }^{23}$ More to the point, is there any published evidence that 
says that ambulatory blood pressure has a greater predictive value for outcome than blood pressure measured by a nurse, or by a patient at home or in a surgery?

The authors claim that ambulatory blood pressure can give a reliable estimate of the patient's white coat effect. The few studies that dealt with this matter showed, however, that the difference between clinic and daytime blood pressure does not reflect the true white coat effect measured in a beat by beat recording during a doctor's visit. ${ }^{45}$ Moreover, recent results indicate that home blood pressure measurement can predict white coat hypertension more precisely than does ambulatory blood pressure. ${ }^{2}$

Although ambulatory blood pressure monitoring can provide unique information on blood pressure variability over 24 hours in well selected patients, there is no proof that mean daytime blood pressure is better in predicting outcome than is self measured blood pressure, blood pressure measured by a nurse, or even blood pressure measured repeatedly in a clinic. Thus, the concept that ambulatory blood pressure should be taken as the reference standard when comparing different measures of blood pressure is not founded on published evidence. More research is needed to really know whether ambulatory blood pressure monitoring can expand the repertoire of tools available to support medical decision making in primary care.

Paolo Palatini professor of medicine Department of Clinical and Experimental Medicine, University of Padua, Via Giustiniani, 2, I-35128-Padua, Italy

palatini@unipd.it

1 Little P, Barnett J, Barnsley L, Marjoram J, FitzgeraldBarron A, Mant D. Comparison of agreement between different measures of blood pressure in primary care and daytime ambulatory blood pressure. BMJ 2002;325:254-9. (3 August.)

2 Palatini P. Too much of a good thing: a critique of overemphasis on the use of ambulatory blood pressure monitoring in clinical practice. J Hypertens 2002;20 (in monitori

press)

Fagard R, Staessen J, Thijs L. Prediction of cardiac structure and function by repeated clinic and ambulatory blood pressure. Hypertension 1997;29:22-9.

4 Parati G, Ulian L, Santucciu C, Omboni S, Mancia G Difference between clinic and daytime blood pressure is not a measure of the white coat effect. Hypertension 1998;31:1185-9.

5 Lantelme P, Milon H, Vernet M, Gayet C. Difference between office and ambulatory blood pressure or real white coat effect: does it matter in terms of prognosis? J Hypertens 2000;18:383-9.

\section{Study was not first or only one}

EDITOR-In the introduction to their study on different blood pressure measurements in primary care Little et al wrote that, to their knowledge, no study in a typical primary care setting has compared such methods with ambulatory monitoring. ${ }^{1}$ At the end of their article they say that no study has compared all available measures in a typical primary care setting with ambulatory blood pressure in patients with newly diagnosed and established hypertension. They overestimated the originality of their study.

From 1992 to 1995 we conducted a comparable study in a typical primary care setting in the Netherlands. ${ }^{2}$ Blood pressure measured by general practitioners, practice nurses, and patients was compared with ambulatory blood pressure in a prospective study over seven months. Ninety nine patients in primary care completed the study: 49 men and 50 women (mean age 48 ). Mean initial systolic blood pressure was 161 $\mathrm{mm} \mathrm{Hg}$ (in the study by Little et al, $161 \mathrm{~mm}$ $\mathrm{Hg}$ ), and mean initial diastolic blood pressure $102 \mathrm{~mm} \mathrm{Hg}$ (study by Little et al, 94 $\mathrm{mm} \mathrm{Hg}$ ).

On theoretical grounds and because two ambulatory blood pressure measurement can be reproduced on different days, we considered averages of ambulatory blood pressure measurements on two days a better reference value than a single ambulatory measurement. ${ }^{3}$ Apart from that, the conclusion of the study by Little et al was in agreement with the older Dutch study. A series of eight blood pressure measurements (on four occasions) by the patient is a good and reliable alternative to ambulatory blood pressure measurement.

Mark Brueren general practitioner

General Practice Stiphout, Kloosterstraat 23a, NL-5708 GM Helmond, Netherlands Mark.brueren@hetnet.nl

1 Little P, Barnett J, Barnsley L, Marjoram J, FitzgeraldBarron A, Mant D. Comparison of agreement between different measures of blood pressure in primary care and daytime ambulatory blood pressure. BMJ 2002;325:254-9. (3 August.)

2 Brueren MM, Schouten HJA, De Leeuw PW, Van Montfrans GA, Van Ree JW. A series of self-measurement by the patient is a reliable alternative to ambulatory blood pressure measurement. Br J Gen Pract 1998:48:1585-9.

3 Brueren MM, Van Limpt P, Schouten HJA, De Leeuw PW, Baren MM, Jan Limpt P, Schouten HJA, De Leeuw PW, he Re JW: the general practitioner or the patient a reliable alternative to shorter study in

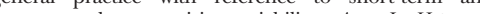
ong-term between-visit variability. $A m J$ Hypertens

\section{Agreement is not same as correlation}

EDITOR-I would like to mention one common misleading use of statistics in the paper by Little et al. You cannot study agreement between different methods with correlation. Correlation coefficients measure association, not agreement. Correlation is the straightness of the line between the values of two variables. When you study agreement, you want to know if the values of the different methods are the same- that is, if they are on the line $y=x$.

You could have perfect correlation between variables $x$ and $y$ with the relation $y=2 x$ and very bad agreement.

Alvine Bissery biostatistician

Clinical Investigation Centre 9201, Assistance

Publique des Hopitaux de Paris/INSERM, Hopital Européen Georges Pompidou, 75908 Paris Cedex 15, France

alvine.bissery@hop.egp.ap-hop-paris.fr

\section{Pleasing some of the people none of the time}

EDITOR-The editorial by Maddern et al was in large part a critical appraisal of our randomised trial of tension free vaginal tape. ${ }^{12}$ We endorse the view expressed by the authors that realistic funding for surgical trials is crucial to their meaningful outcome, and that contingency funding should be available so that trials are not underpowered. We accept that our failure to recruit up to the calculated sample size in this trial has an inevitable adverse effect on the power of its conclusions. We emphasised this in our publication and in a subsequent commentary. $^{23}$

It must be recognised, however, that statistical power is a fickle concept. Our own trial sought to recruit 394 patients, on the assumption of $90 \%$ cure from colposuspension, and that $10 \%$ difference in cure would be clinically important. The trial achieved recruitment of only 344 patients, and, given that the cure from colposuspension was lower than that expected from the literature, the study had only $50 \%$ power to detect a $10 \%$ difference or $80 \%$ power to detect a $15 \%$ difference between the procedures under review. ${ }^{2}$ The ongoing Medical Research Council trial of laparoscopic colposuspension seeks to recruit 290 patients on the assumption that colposuspension has a $80 \%$ cure and that a $15 \%$ difference in cure is clinically important. ${ }^{4}$ Surely this would mean that our own trial assumptions were not unreasonable at the time they were made.

Maddern et al express concern at the biases inherent in our study favouring tension free vaginal tape, on the basis of our failure to test assumptions in the analysis and our handling of missing data. We recognise that had we explored the range of possible scenarios-for example, that all missing data from one arm represented treatment failure and from the other arm treatment success, our conclusions may have been different. As the authors point out, however, women treated with tension free vaginal tape had shorter operating time, reduced hospital stay, less adverse impact on quality of life surrounding their surgery, and returned to normal activities more rapidly. Although the trade-offs that patients make in their decisions regarding surgical treatment are difficult to quantify, it is clear that more are choosing the less invasive approach, and that secondary trial outcomes may be of primary significance to patients.

The broad definition of intention to treat is clear, but its full application is possible only when complete outcome data are available for all randomised subjects. ${ }^{6}$ The handling of post-randomisation withdrawals is undoubtedly crucial in the interpretation of cure in surgical trials. ${ }^{37}$ In our initial submission for publication, we were concerned to avoid bias favouring the new intervention resulting from differential withdrawal rates; hence we had undertaken what we described as a "modified intention to treat analysis," including only those patients undergoing surgery. The advice from the editors and reviewers of our manuscript was that all patients randomised must be included in the analysis. It is therefore something of a frustration to us that Maddern et 
al now raise this criticism under an editorial banner.

Paul Hilton consultant gynaecologist
Karen L Ward specialist registrar
Directorate of Women's Services, Royal Victoria
Infirmary, Newcastle upon Tyne NE1 4LP

1 Maddern G, Middleton P, Grant A. Urinary stress incontinence. BMJ 2002;325:789-90. (12 October.)

2 Ward KL, Hilton P. Prospective multicentre randomised trial of tension-free vaginal tape and colposuspension as primary treatment for stress incontinence. $B M J$ 2002;325:67-70. (13 July.)

3 Hilton P. Trials of surgery for stress incontinencethoughts on the "Humpty Dumpty principle." Br J Obste Gynaecol 2002;109:1081-8.

4 The MRC COLPO Trial-ISRCTN14969683. In: Register of Current Controlled Trials; www.controlled-trials.com (accessed 19 Oct 2009)

5 Tincello DG, Alfirevic Z. Important clinical outcomes in urogynecology: Views of patients, nurses and medical staff. Int Urogynecol J Pelvic Floor Dysfunction 2002;13:96-8.

6 Hollis S, Campbell F. What is meant by intention to treat analysis? Survey of published randomised controlled trials. BMJ 1999;319:670-4.

7 Fergusson D, Aaron S, Guyatt G, Hebert P. Postrandomisation exclusions: the intention to treat principle and excluding patients from analysis. BMJ 2002;325:652-4.

\section{Retaining nurses in the NHS}

Extent of shortage will be known only when nurses spend all their time nursing

EDITOR-Finlayson et al chronicled the problems affecting nursing and the environmental factors contributing to the current shortages. ${ }^{1}$ Embedded in their story is, however, a crucial element of the problem. Evidence from the United States, Canada, and Germany has found that nurses spend time performing functions not related to their professional skills, such as cleaning rooms or moving food trays. Nurses also reported more pressure to take up management responsibility, taking them away from the direct care of patients.

This means that, although a shortage of professional nursing may exist, a shortage of nurses might not. Nurses spend much of their time doing things that should be delegated to others and not enough of their time doing what they are educated to do. This is inefficient and demoralising and accounts for at least some of the widespread job dissatisfaction in the profession. Thus far, policy responses have come in one of two forms: raising salaries (favoured in Canada) and increasing capacity in nursing education programmes (favoured in many jurisdictions).

Paying nurses more money may be just, but it will not by itself produce more nurses or make them more content with their working conditions once the transitory glow of the extra money dims. Increasing the supply of new nurses may turn out to be perversely ineffective if overall numbers grow, nurses perform even more nonnursing tasks, and system costs rise because highly trained people are used inefficiently.

The problem is not restricted to nursing. A recent systematic review reported that nurse practitioners can do what general practitioners typically do in a wide variety of settings. ${ }^{2}$ In health care it has proved difficult to get the division of labour right, and the complex array of professions, regulatory and licensing bodies, and organisational structures renders rapid adaptation to changing circumstances difficult.

These realities show that we should not rush headlong towards solutions that leave some fundamental problems unaddressed The first obligation to the health system and to nurses is to ensure that the nursing practice matches their skills. Only when nurses are allowed to withdraw from areas of non-nursing activity and do what they should be doing will we know the true extent of the nursing shortage-if it exists at all Achieving a proper division of labour that respects and maximises professionals' competencies will make the healthcare system more effective and efficient. It will also create a better motivated and contented workforce.

Steven J Lewis adjunct professor of health policy 3330 Hospital Drive NW, Calgary, AB, Canada T2N 4N1

Steven.Lewis@shaw.ca

1 Finlayson B, Dixon J, Meadow S, Blair G. Mind the gap: the extent of the NHS nursing shortage. BMJ 2002;325:538 41. (7 September)

2 Horrocks S, Anderson E, Salisbury C. Systematic review of whether nurse practitioners working in primary care can provide equivalent care to doctors. BMJ 2002;324:819-23

\section{Nurses' loyalty may be underestimated}

EDITOR-The nursing shortage described by Finlayson et al is not new. ${ }^{1}$ It has been a recurrent problem over decades, and it is set to worsen. The proposed new expenditure on the NHS will have a profound, but as yet unknown, effect on the demand for nursing staff, such that serious shortages in the short run are likely to constrain planned capacity expansions.

The authors conclude that recruitment is less problematic than retention. Our own analysis indicates that attrition from the nursing profession is not as severe as from teaching. ${ }^{2}$ We used data from the British household panel survey (a representative sample of the United Kingdom's population) to trace all qualified nurses and teachers under the age of 60 . We found that $42.6 \%$ of nurses, compared with $53.9 \%$ of teachers, had left their professions between 1991 and 1996. Roughly equal proportions were not working $(14.5 \% v 15.1 \%)$. Of those who had left the nursing profession for other work, $50 \%$ were employed in other caring occupations, such as social or child care; only $20 \%$ of leaving teachers remained employed in education.

Comparing nurses who stayed and left, those who left were significantly older and less likely to be doing two jobs. They reported less shift working, earned on average $7 \%$ less, and expressed more satisfaction with their jobs than those remaining in nursing. Some amount of wastage is to be expected from any profession, and nurses seem to compare favourably with teachers. But $33 \%$ of working nurses, compared with $13 \%$ of teachers, reported that they were not satisfied with their jobs. What keeps these nurses in nursing? Is it dedication to the profession, home ties, or lack of better opportunities?
Deepening shortages in future years may generate higher rewards that mitigate pay inequalities in nursing: teachers in the sample from the British household panel survey averaged $50 \%$ higher incomes than nurses. The concern is, however, that we will continue to rely on nurses' goodwill.

Heather M Gage senior lecturer

Department of Economics, University of Surrey, Guildford, Surrey GU2 7XH

h.gage@surrey.ac.uk

Rosemary Pope professor of nurse education

European Institute of Health and Medical Sciences, University of Surrey

Fiona Lake research assistant

Goldman Sachs, London FC4A 2BB

1 Finlayson B, Dixon J, Meadow S, Blair G. Mind the gap: the extent of the NHS nursing shortage. BMJ 2002:325:53841. (7 September.)

2 Gage H, Pope R, Lake F. Keeping nurses nursing: a quantitative analysis. Nursing Times 2001;97:35-7.

\section{People starting nurse training should think again}

EDITOR-With reference to the article by Finlayson et al on the problems retaining nurses in the NHS, ${ }^{1}$ I worked as a nurse in the NHS for 18 years, 15 years of which were spent in emergency medicine as both a staff nurse and a sister. I encountered a lot of violence and aggression from patients during this time.

After a particularly frightening assault on me-in which I was jumped on from behind, beaten over the head with a telephone, and strangled-I became concerned about my safety and that of my colleagues. I voiced my concerns to the management and said that I did not feel that I could carry on working in emergency care unless we were provided with full time security. I was told that this cost could not be justified.

I therefore resigned my post and left the NHS as soon as I was able to secure a position. I have found that there is life outside the NHS where my work is appreciated by both my managers and my clients and where my opinion is both sought and valued. I was (and still am) a highly qualified emergency nurse and emergency nurse practitioner, but nothing could now compel me to return to the NHS. I would advise anyone thinking of starting nurse training to think again.

Janet M Pinder medical litigation executive, Russell Jones and Walker, Sheffield

Barnsley S74 8DZ

J.Pinder@jrw.co.uk

1 Finlayson B, Dixon J, Meadow S, Blair G. Mind the gap: the extent of the NHS nursing shortage. BMJ 2002;325:53841. (7 September.)

\section{Poor pay is not the only reason}

EDITOR-Finlayson et al highlighted the problems of retaining nurses in the NHS. ${ }^{1}$ Those of us working in the NHS are not surprised that $30 \%$ of newly qualified nurses seem not to want to stay in the new "modernised" health service. What is surprising is that is has taken so long for this to become apparent.

Most feel undervalued, overworked, and abused by a government whose main 
message seems to be that these workers, who for years have devoted themselves to an under-resourced and badly run NHS, know less well than newly elected politicians how they should perform their duties. Worse, when things go wrong, a whole industry emerges dedicated to finding, humiliating, and destroying a scapegoat.

Most workers in the NHS have already shown their intelligence, application, and dedication to sick people by undergoing arduous professional training. They are then quizzed about their HIV status and possible criminal record before they work in the crumbling edifices that are typical of most NHS hospitals. Here they are pressured to do their job and cover for the unreasonable expectations encouraged by government dogma.

Naturally, mistakes can happen, and a few will abuse the system in which they work. The spin doctors are then wheeled out, Health Secretary Alan Milburn puts on his enraged face, more millions are diverted from frontline health care, and if someone can be humiliated on the steps of the General Medical Council or have their pension threatened, so much the better. By contrast, the destruction of lives, sickness, or death resulting from stock exchange losses, government mistakes, or dubious insurance deals seems to be accepted as due to market forces: someone retires with a golden handshake.

Poor pay is often cited as the problem but, although this is undoubtedly a factor, the realities of recent supposed pay increases (up to $20 \%$ for consultants widely announced in the media) have been much less attractive. Take a look round where you live, and see who has the big house, the fine furniture, the new large car, and the trips abroad. How many of these got their lifestyle working for the NHS? Unfortunately, the idealism that fired us in youth declines as we approach retirement, and the new generation questions whether it wishes to follow in our footsteps.

F David Beggs consultant thoracic surgeon Nottingham City Hospital, Nottingham NG5 1PB dbeggs@ncht.trent.nhs.uk

1 Finlayson B, Dixon J, Meadow S, Blair G. Mind the gap: the extent of the NHS nursing shortage. BMJ 2002;325:53841. (7 September.)

\section{Thrombolysis for acute ischaemic stroke}

\section{Trial participants need to be informed of uncertainty principle}

EDITOR-Koops and Lindley involved consumers in the design of a randomised trial of thrombolysis in acute stroke and published the associated patient information sheet. ${ }^{12}$ Critical appraisal of trial information leaflets benefits the manner in which they are conceived and formulated.

In addition to a limited number of eligibility criteria, the trial notably uses the uncertainty principle for determining eligibility of patients. ${ }^{3}$ The multicentre research ethics committee requested an explanation of this principle in lay language in the information sheet:

Your doctor believes that there is no proof that rt-PA will definitely help you. If your doctor was convinced that you should be given the new treatment (for whatever reason) you would have been given it. If your doctor believed that you should definitely avoid rt-PA treatment, you will not receive it and you would not be invited to join this sort of study. Having weighed up the pros and cons of treatment your doctor feels there is

"an absence of proof" for rt-PA for your particular circumstances. You are therefore eligible for the trial.

Uncertainty may be present at three levels: the community of "expert" practitioners (also relevant to research ethics committees that must approve the trial); the patient's doctor (who has to decide whether to participate in the trial and then offer enrolment to particular patients); and the patient (who has to decide whether to enrol). ${ }^{4}$ The language above clearly addresses the doctor's uncertainty, but it does not adequately clarify that the ultimate decision is the patient's or provide any guidance pertinent to that decision.

Trial participation is a rational choice when an adequately informed patient is maximally uncertain -in equipoise-as to the relative efficacy and safety of comparator interventions. The patient also needs to be in equipoise about any other interventions available outside the trial, including the possibility of participating in another relevant trial. As Lilford has described, the concept of patient equipoise may be understood in the context of utility theory. ${ }^{5}$ Provision of the necessary information, and a discussion of this decision strategy, should be a part of the consent process. The challenge, of course, is to accomplish this in a manner comprehensible to potential participants.

Language such as the following may be considered for such a trial:

The trial's investigators believe patients like you may benefit from rt-PA. Because this is not yet known for sure, this trial is being run with a large number of participants. Because of this uncertainty, your doctor believes participation is a reasonable option for you. If, after discussing the potential benefits and harms of rt-PA, and other alternatives, with your doctor, you are also completely uncertain, joining the trial is a good option. This is called the uncertainty principle, and it helps doctors and patients decide what to do about clinical trials. Also, for a patient, deciding to be randomised in this situation gives one the best odds $(50 \%)$ of getting the preferred treatment, no matter which one is subsequently shown to be better, on average, after the trial is completed and the results analysed.

Howard Mann associate professor

Department of Radiology, 1A71 University Hospital, 50 North Medical Drive, Salt Lake City, UT 84132, USA

howard.mann@hsc.utah.edu

1 Koops L, Lindley RI. Thrombolysis for acute ischemic stroke: consumer involvement in design of new randomised controlled trial. BMJ 2002; 325:415. (24 August.)
2 Third International Stoke Trial (IST-3). Patient information sheet. bmj.com/cgi/content/full/325/7361/415/ DC1 (accessed 11 November 2002).

3 Third International Stoke Trial. IST-3: Thrombolysis for acute stroke [protocol]. www.dcn.ed.ac.uk/ist3/protocol/ protocol.asp (accessed 11 November 2002).

4 Sackett DL. Uncertainty about clinical equipoise. CMAJ 2001; 164:1831-32.

5 Lilford RJ. Equipoise is not synonymous with uncertainty. BMJ 2001;323:574

\section{Good quality research that addresses patients' needs is required}

EDITOR-Good quality trials require careful preliminary research if they are to attract the people they are intended to help: the patients. To achieve this the outcome being sought must be relevant to patients and the scientific hypothesis feasible and acceptable to clinicians and patients alike. ${ }^{1}$ A report of research planned together with consumers describes how their involvement helped to refine trial consent procedures and led to an ethically acceptable trial design in the problematic clinical area of acute ischaemic stroke for a treatment with potentially fatal consequences. $^{2}$

The thorough preliminary explorative qualitative and quantitative research led to a randomised controlled trial granted full ethics approval that included a procedure for waiver of consent. Focus group participants recognised the ethical dilemmas, suggesting solutions that led to an acceptable trial design for all parties and substantial improvements in the information leaflets. Insights were obtained on the levels of risk deemed acceptable by patients, the appropriate language and terms in information leaflets, different levels of consent, etc, in an enjoyable and mutually educative collaborative undertaking. This sensitive method is in stark contrast to evidence obtained from systematic reviews of clinical trials and animal experiments that ran simultaneously, relating to the use of nimodipine in acute ischaemic stroke. ${ }^{3}$ It raises many questions.

How is it possible that 22 trials of nimodipine involving 6468 patients could have been given ethics approval? How was consent obtained from these participants? Did researchers provide systematic reviews of similar research? Were researchers aware of duplications? How were phase I and II trials allowed to proceed, let alone phase III therapeutic trials, if the animal experiments were only then being undertaken simultaneously-and ultimately found no convincing evidence to start clinical trials?

If ethics committees are to be the guardians of research, ${ }^{4}$ they, and trial sponsors, must instigate procedures to ensure that researchers provide complete systematic reviews when submitting research proposals, as the Medical Research Council now requires. Until we achieve a balanced cooperation between clinician researchers, patients, funders, and ethicists, resources (both human and financial) will continue to be wasted. Only by means of enlightened and fruitful collaborations such as those described in Koops and Lindley's report, where patients are recognised and treated as being competent, rational and resourceful, and not the "irrational, passive, forgetful and incompe- 
tent" entity so often depicted, shall we economically achieve good quality research that truly addresses patients' needs. ${ }^{3}$

Hazel Thornton independent advocate for quality in research and healthcare

"Saionara," 31 Regent Street, Rowhedge, Colchester CO5 7EA

1 Thornton H, Dixon-Woods M. Recruitment of women into trials. Lancet 2002;359:104-5

2 Koops L, Lindley RI. Thrombolysis for acute ischaemic stroke: consumer involvement in design of new randomised controlled trial BMJ 2002; 325:415-7. (24 August.)

3 Sandercock P, Roberts I. Systematic reviews of animal experiments. Lancet 2002:360:586

Refractor. Guardianship. Lancet 2001;357:1808.

5 Dixon-Woods M. Writing wrongs? An analysis of

published discourses about the use of patient information published discourses about the use of
leaflets. Soc Sci Med 2001;52:1417-32.

\section{When medical students go off the rails}

\section{Lack of continuity from admission to} postgraduate career is a problem

EDITOR-The editorial by Rubin highlights a difficult and complex subject, not least because a medical student can go off the rails in many ways and for many reasons.

Our experience at Imperial College with students who have failed their exams is that many of them have had major problems in their non-academic lives and need help coping with them. What is sad, but probably not surprising, is how few have tried to obtain help when the difficulties started or their work became affected. Of course these are not the students that Rubin was considering, although those who misbehave often, although not always, do badly academically.

The fitness to practice procedures that most medical schools are setting up are an important step forward. Obtaining evidence that is defensible will be more of a challenge. Often it is a number of small events that should set the alarm bells ringing. Ensuring that these events are recorded may be difficult.

What about students with health problems? I am aware of students with depression who suddenly disappear. Having depression should not disqualify students from becoming doctors, but disappearing might, even if it is linked to a treatable illness.

A major problem is the lack of continuity from admission to medical school and postgraduate career. Not only should information be passed forward but feedback should be given to the school. This should be an area for research. If at all possible we should learn more about the student career of doctors who perform poorly. Even with all possible precautions in place, some students will still surprise us. There is much to learn, and given the few students about whom this is an issue in each school, much to be gained by sharing information.

Jonathan H S Fuller senior lecturer

Department of Primary Health Care and General

Practice, Faculty of Medicine, Imperial College,

London W6 8RP

jonathan.fuller@btinternet.com

1 Rubin P. When medical students go off the rails. BMJ 2002;325:556-7. (14 September.)
In New York standards are set and tools for help given at start of medical school

EDITOR-With reference to the editorial by Rubin, ${ }^{1}$ in the first week of the first year of medical school we attempt to set a standard of professionalism. We ask students to reflect on why they came here, what they expect of fellow doctors, and what makes joining the medical profession different from other occupations.

Substance abuse affects about $10 \%$ of those in the medical profession at one time or another. To enforce this awareness, we invite a doctor in recovery to speak to students first hand about his or her experience.

Finally, we give new medical students tools for help and reporting (New York state has very strict and specific guidelines). Our message is that this is important, a priority, and must be recognised from the start

Sheila Otto instructor

Albany Medical College, MC 153, 47 New Scotland Avenue, Albany, NY 12206, USA

ottos@mail.amc.edu

1 Rubin P. When medical students go off the rails. $B M$ J 2002;325:556-7. (14 September.)

\section{CONSORT statement requires} closer examination

EDITOR-Several correspondents have criticised the HOPE investigators for focusing on relative effects when the absolute benefit was very small. Twisselmann, in her summary of many responses on the website, comments: "It was noted that only the relative risk reduction was given in the study. This should have been accompanied by data on absolute risk reduction and number needed to treat and even number needed to harm (as per CONSORT guidelines)."

This sentence may accurately reflect comments on bmj.com, but it misrepresents the CONSORT statement. Although we agree that in many cases it is helpful to present results as both reduction in relative risk and reduction in absolute risk, $\mathrm{CON}$ SORT makes no such recommendation.

Badrinath observes that if general agreement is reached then the next CONSORT guidelines should include a statement that, whenever applicable the results of clinical trials should include the numbers needed to treat. ${ }^{1}$ Clearly, no such consensus exists, which is why CONSORT does not recommend that the number needed to treat is always given. Rather, the CONSORT explanatory document says simply: "For both binary and survival time data, expressing the results also as the number needed to treat for benefit (NNTB) or harm (NNTH) can be helpful."

The choice between relative and absolute measure of treatment effect continues to cause debate, yet no such choice is needed. In some situations, results can usefully be presented as both relative and absolute effects. However, that could be cumbersome in a journal article for every primary and secondary outcome presented. Authors and journals demand and deserve some flexibility in presenting their results. CONSORT recommends merely the basics and avoids subjective assessments on the details of presentation. Simply, we advocate that authors provide a summary of results for each group and the estimated effects size and its precision, which entails providing adequate raw data so that readers can calculate either a relative or absolute measure if it is not provided and they deem it necessary.

Other authors have incorrectly attributed certain reporting criteria to CONSORT. ${ }^{3}$ We are encouraged by the growing dissemination of the CONSORT statement as a way to help improve the quality of reporting randomised trials, but we also encourage a closer examination of its content.

Douglas G Altman professor of statistics in medicine Cancer Research UK Medical Statistics Group,

Centre for Statistics in Medicine, Institute of Health Sciences, Oxford OX3 7LF

doug.altman@cancer.org.uk

Kenneth F Schulz vice president of quantitative sciences

Family Health International, PO Box 13950, Research Triangle Park, NC 27709, USA

David Moher director

Chalmers Research Group, Children's Hospital of Eastern Ontario, 401 Smyth Road, Ottawa, ON, Canada K1H 8L1

1 Badrinath P, Wakeman AP, Wakeman JG, Yudkin JS, Parmar MS, Twisselmann B. Preventing stroke with ramipril. BMJ 2002;325:439. (24 August.)

2 Altman DG, Schulz KF, Moher D, Egger M, Davidoft, Elbourne D, et al, for the CONSORT Group. The revised CONSORT statement for reporting randomized trials: CONSORT statent 2001:134:663-94.

3 Schulz KF, Moher D, Altman DG. Interpreting the number needed to treat.JAMA 2002;288:831.
nesulz

\section{Making coffee has advantages}

EdITOR-Fox and Davies ask whether superstitious behaviour can reduce work stress. As a radiologist $\mathrm{I}$ find one of the most irritating and stressful things that can ruin an ultrasound list are long delays while waiting for "emergency" inpatients to come down from the wards. These delays are multifactorial, and common reasons range from porters not answering their bleeps to patients being washed.

The easiest way to speed up this process is to make a cup of coffee. The patient will inevitably arrive just as you take the first sip. This system has the added advantage of reducing your caffeine intake, thus avoiding the additional stress of sleepless nights.

John Addison consultant radiologist Dr Gray's Hospital , Elgin, Moray IV30 1TS j.ea.addison@talk21.com

1 Fox A, Davies P. Can superstitious behaviour reduce work stress? BMJ 2002;325 (suppl): S83. (14 September.)

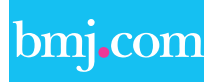

\section{Rapid responses}

Correspondence submitted electronically is available on our website 